\title{
Electrochemical Behavior and Specific Adsorption of an Iodide-based Ionic Liquid on Au(111) \\ Hiroyuki UEDA, ${ }^{\text {a Katsuhiko NISHIYAMA, }}$, and Soichiro YOSHIMOTO ${ }^{\mathrm{b}, *}$
}

\author{
a Graduate School of Science and Technology, Kumamoto University, \\ 2-39-1 Kurokami, Chuo-ku, Kumamoto 860-8555, Japan \\ b Division of Materials Science \& Chemistry, Faculty of Advanced Science \& Technology, \\ Kumamoto University, 2-39-1 Kurokami, Chuo-ku, Kumamoto 860-8555, Japan
}

* To whom correspondence should be addressed.

\begin{abstract}
The electrochemical behavior and specific adsorption of an ionic liquid, 1-butyl-3-methylimidazolium iodide, on a $\mathrm{Au}(111)$ electrode surface were investigated via voltammetric analyses, X-ray photoelectron spectroscopy (XPS), and scanning tunneling microscopy (STM). The electrochemical potential window and the reductive desorption of I adatoms were evaluated using voltammetric techniques. The XPS and STM results supported the specific adsorption of I adatoms on Au(111). Furthermore, high-resolution STM images revealed the formation of characteristic nanostructured rings consisting of imidazolium cations on I adatoms for the first time.
\end{abstract}

(c) The Electrochemical Society of Japan, All rights reserved.

Keywords : Ionic Liquid, Specific Adsorption, Nanostructured Ring, Scanning Tunneling Microscopy

\section{Introduction}

Ionic liquids (ILs) have been extensively studied in the field of secondary batteries because they have excellent properties, such as high ionic conductivities, wide electrochemical windows, low vapor pressures, and high thermal stabilities. Investigation of the electrical double-layer structure of IL/electrode interfaces provides a detailed understanding of the electron transfer pathway. Indeed, the structure of the electrical double-layer is strongly affected by the cation and anion composition of ILs. ${ }^{1}$ A potential distribution produced by the electrical double-layer has been proposed. $^{2}$ In addition, distinctive interfacial phenomena dependent on the orientation of IL cations in the double-layer region have been reported. ${ }^{3-5}$

From the standpoint of electrochemical surface science, it is important to understand and to characterize the specific adsorption of ions and the dynamics of phase transitions. ${ }^{6-8}$ In particular, the specific adsorption of anions such as halides, sulfate, and cyanide on metal electrode surfaces is well known. ${ }^{6-8}$ In the field of IL electrochemistry, ILs consisting of alkylmethylimidazolium $\left(\left[\mathrm{C}_{n} \mathrm{mim}\right]^{+}\right)$or butylmethylpyrrolidinium $\left([\mathrm{BMP}]^{+}\right)$cations and bistrifluoromethylsulfonylamide $\left(\left[\mathrm{Tf}_{2} \mathrm{~N}\right]^{-}\right)$anions are often used because of their high chemical stability. ${ }^{9-17}$ The electrochemical interfaces of ILs have been studied using various methods, such as sum frequency generation (SFG), ${ }^{9} \mathrm{X}$-ray photoelectron spectroscopy (XPS), ${ }^{10,11}$ surface X-ray scattering (SXS), ${ }^{12,13}$ infrared spectroscopy, ${ }^{14}$ and scanning tunneling microscopy (STM). ${ }^{15-17}$ However, to our best knowledge, details on the adsorption and adlayer structures of ILs are still limited owing to the weak adsorption of $\left[\mathrm{Tf}_{2} \mathrm{~N}\right]^{-}$, although highly ordered adsorption of cations, such as $\left[\mathrm{C}_{6} \mathrm{mim}\right]^{+}$ and $[\mathrm{BMP}]^{+}$, has been observed at room temperature using video STM. ${ }^{16,17}$ The only example of a $2 \mathrm{D}$ crystalline phase is $[\mathrm{BMP}]\left[\mathrm{Tf}_{2} \mathrm{~N}\right]$ on $\mathrm{Ag}(111)$, which was observed below $100 \mathrm{~K}$ under ultrahigh vacuum (UHV). ${ }^{18}$

Herein, to obtain a precise understanding of the formation of electrical double-layer structures and the phase transition at IL electrochemical interfaces, we focused on the electrochemical behavior and adlayer structures of 1-butyl-3-methylimidazolium iodide $\left(\left[\mathrm{C}_{4} \mathrm{mim}\right][\mathrm{I}]\right)$. This IL was chosen because it is a liquid at room temperature, it is commercially available with high purity, and the specific adsorption of iodine is expected to occur on a $\mathrm{Au}(111)$ electrode surface. ${ }^{6,8}$

\section{Experimental}

$\left[\mathrm{C}_{4} \mathrm{mim}\right][\mathrm{I}]$ (advanced material research grade, Kanto Chemical Co. Ltd.) was used after drying at approximately $80^{\circ} \mathrm{C}$ under vacuum conditions for more than $6 \mathrm{~h}$.

The Au(111) single crystal electrode was prepared by Clavilier's method. ${ }^{19}$ After the electrode surface was annealed in a hydrogen flame and then cooled in air, the $\mathrm{Au}(111)$ electrode was introduced into a vacuum-type glove box (UN650F, UNICO Corp.). Linear sweep voltammetry (LSV) and cyclic voltammetry (CV) were performed using an electrochemical analyzer (Model 610D, CH Instruments, Inc.). The water and oxygen concentrations were maintained at less than $5 \mathrm{ppm}$ using a gas recycling purification system (MF-71, UNICO Corp.). Pt wires were used as the counter and quasi-reference electrodes. All electrochemical measurements were conducted at room temperature $\left(25 \pm 1^{\circ} \mathrm{C}\right)$. The potential value was calibrated to the redox potential of ferrocene/ferrocenium $\left(\mathrm{Fc} / \mathrm{Fc}^{+}\right)$.

XPS was performed on $\left[\mathrm{C}_{4}\right.$ mim $][\mathrm{I}]$-adsorbed $\mathrm{Au}(111)$ samples prepared by the following three steps: (1) the $\mathrm{Au}(111)$ electrode was placed in contact with $\left[\mathrm{C}_{4} \mathrm{mim}\right][\mathrm{I}]$ under an $\mathrm{Ar}$ atmosphere, (2) the electrode in contact with the IL was kept at the open circuit potential (OCP, ca. $-0.55 \mathrm{~V}$ vs. $\mathrm{Fc} / \mathrm{Fc}^{+}$) or $-2.3 \mathrm{~V}$ vs. $\mathrm{Fc} / \mathrm{Fc}^{+}$for $1 \mathrm{~min}$, and (3) the electrode was thoroughly washed in acetone under ultrasonication for $1 \mathrm{~min}$. Notably, the adlayer structure of iodine prepared from a KI aqueous solution was identical to the adlayer structure observed under UHV after transferring the substrate into a UHV chamber, ${ }^{20}$ indicating that the adlayer structure is not influenced by the washing process. XPS measurements were conducted using a PHI 5800 ESCA system (ULVAC-PHI, Inc.) with monochromatized $\mathrm{AlK} \alpha$ radiation (photon energy of $1486.6 \mathrm{eV}$ ). The system was operated under a background pressure of less than $1 \times 10^{-9}$ Torr. All spectra were collected with an overall energy resolution of $0.48 \mathrm{eV}$. The binding energies were calibrated using the $\mathrm{C} 1 \mathrm{~s}$ peak at $284.5 \mathrm{eV}$. 
(a)

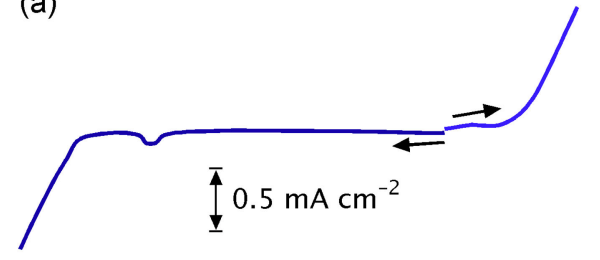

(b)

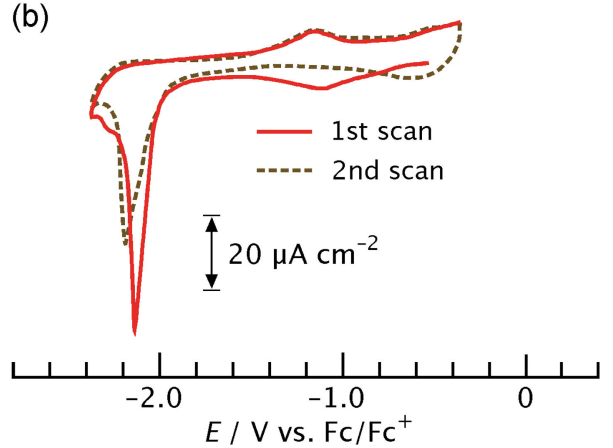

Figure 1. (a) LSV and (b) $\mathrm{CV}$ profiles of a $\mathrm{Au}(111)$ electrode in $\left[\mathrm{C}_{4} \mathrm{mim}\right][\mathrm{I}]$ recorded at a scan rate of $50 \mathrm{mV} \mathrm{s}^{-1}$. The scan was started at $-0.55 \mathrm{~V}$ vs. $\mathrm{Fc} / \mathrm{Fc}^{+}$(nearly equal to the $\mathrm{OCP}$ ).

STM measurements were performed under ambient conditions using a Nanoscope E system (Digital Instruments) with a highresolution scanner (HD-0.5I). The tungsten tip was etched in $1 \mathrm{M}$ $\mathrm{KOH}$. STM images were obtained in constant-current mode.

\section{Results and Discussion}

First, the electrochemical behavior of a $\mathrm{Au}(111)$ electrode was examined in $\left[\mathrm{C}_{4} \mathrm{mim}\right][\mathrm{I}]$. Figure 1a shows the LSV profile of the $\mathrm{Au}(111)$ electrode in $\left[\mathrm{C}_{4} \mathrm{mim}\right][\mathrm{I}]$. The electrochemical potential window $\left(E_{\mathrm{pw}}\right)$, estimated from the difference in the potentials at which the current density started increasing or decreasing rapidly on the cut-off current density of $\pm 1.0 \mathrm{~mA} \mathrm{~cm}^{-2}$, was approximately $2 \mathrm{~V}$. In general, $\left[\mathrm{C}_{n} \mathrm{mim}\right]^{+}$-based ILs have wide $E_{\mathrm{pw}}$ of over $4 \mathrm{~V}^{4}$ However, the $E_{\mathrm{pw}}$ of $\left[\mathrm{C}_{4} \mathrm{mim}\right][\mathrm{I}]$ was quite narrow because the dissolution of $\mathrm{Au}$ is caused by the formation of gold complexes with iodide. ${ }^{21}$ Figure $1 \mathrm{~b}$ shows a typical $\mathrm{CV}$ profile of the $\mathrm{Au}(111)$ electrode in $\left[\mathrm{C}_{4} \mathrm{mim}\right][\mathrm{I}]$. An iodine adlayer is expected to form on the $\mathrm{Au}(111)$ electrode surface after the electrode surface comes into contact with $\left[\mathrm{C}_{4} \mathrm{mim}\right][\mathrm{I}]$. Small and large reductive peaks were observed at $-1.15 \mathrm{~V}$ and $-2.17 \mathrm{~V}$ vs. $\mathrm{Fc} / \mathrm{Fc}^{+}$, respectively, in the first negative scan. If one-electron reductive desorption of adsorbed iodine atoms occurs at the $\mathrm{Au}(111)$ electrode, the following equation is proposed:

$$
\mathrm{I}-\mathrm{Au}+\mathrm{e}^{-} \rightarrow \mathrm{I}^{-}+\mathrm{Au}
$$

Based on the electronic charge consumed by the reduction process, the surface excess of iodine was calculated to be $(8.0 \pm 0.7) \times$ $10^{-10} \mathrm{~mol} \mathrm{~cm}^{-2}$. This value is almost identical to that obtained in a $\mathrm{KI}$ aqueous solution, as reported by Weaver's group. ${ }^{22}$ The reductive currents were gradually suppressed by potential cycling, which is associated with the formation of a $\left[\mathrm{C}_{4} \mathrm{mim}\right]^{+}$adlayer after the reduction of the I adatoms.

The chemical species on the $\mathrm{Au}(111)$ electrode surface in $\left[\mathrm{C}_{4} \mathrm{mim}\right][\mathrm{I}]$ were investigated by XPS. Figure 2 shows the XPS spectra in the I3d and N1s binding energy regions. Two energetic peaks were observed at $618.5 \mathrm{eV}$ and $630.0 \mathrm{eV}$ (Fig. 2a), assigned to $\mathrm{I} 3 \mathrm{~d}_{5 / 2}$ and $\mathrm{I} 3 \mathrm{~d}_{3 / 2}$, respectively. These peak positions were in good agreement with literature values. ${ }^{11}$ This result implies that specific adsorption of iodide occurs in $\left[\mathrm{C}_{4} \mathrm{mim}\right][\mathrm{I}]$. In the N1s XPS spectrum (a)

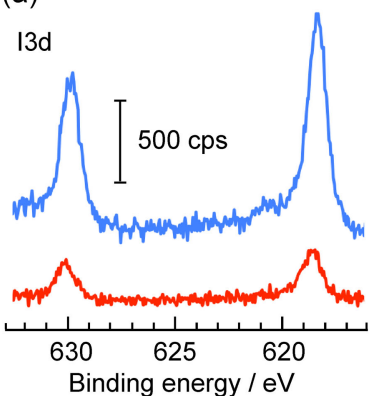

(b)

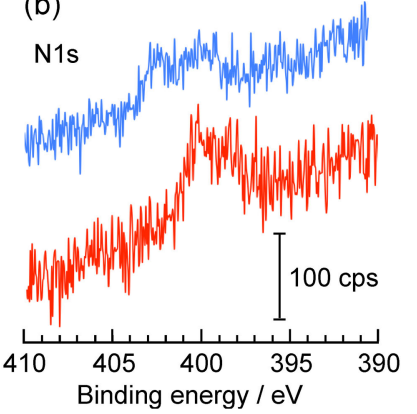

Figure 2. (a) I3d and (b) N1s XPS spectra of $\mathrm{Au}(111)$ prepared in $\left[\mathrm{C}_{4} \mathrm{mim}\right][\mathrm{I}]$ by holding at $-0.55 \mathrm{~V}$ (blue) and $-2.3 \mathrm{~V}$ (red) vs. $\mathrm{Fc} /$ $\mathrm{Fc}^{+}$for $1 \mathrm{~min}$.

shown in Fig. 2b (blue), a broad peak with low intensity is located in the region between $398 \mathrm{eV}$ and $405 \mathrm{eV}$, indicating the adsorption of imidazolium cations, $\left[\mathrm{C}_{4} \mathrm{mim}\right]^{+}$, onto the $\mathrm{I}-\mathrm{Au}(111)$ surface. According to a previous report, the N1s spectrum for $\left[\mathrm{C}_{4} \mathrm{mim}\right]^{+}$ exhibits a peak at $401.6 \mathrm{eV}^{10}$ When the $\mathrm{Au}(111)$ electrode was prepared by holding the electrode potential at $-2.3 \mathrm{~V} \mathrm{vs.} \mathrm{Fc} / \mathrm{Fc}^{+}$for $1 \mathrm{~min}$, the $\mathrm{I3d}$ peaks decreased (Fig. 2a, red). Note that approximately $1 \mathrm{~min}$ is required to transfer the $\left[\mathrm{C}_{4} \mathrm{mim}\right][\mathrm{I}]$-adsorbed $\mathrm{Au}(111)$ substrate into acetone for washing because the electrode is removed from the glove box. Nevertheless, a clear decrease was observed for the I3d peaks. This result implies that the reformation of I adatoms is quite slow and a hysteresis against the applied potential occurs owing to the displacement of $\left[\mathrm{C}_{4} \mathrm{mim}\right]^{+}$on the $\mathrm{Au}(111)$ surface after the reduction of I adatoms. In contrast to the I3d spectrum, the intensity of the peak around $400 \mathrm{eV}$ in the N1s spectrum slightly increased through a negative potential step (Fig. 2b, red). In addition, the peak shifted to a lower binding energy, suggesting that $\left[\mathrm{C}_{4} \mathrm{mim}\right]^{+}$was directly adsorbed onto the $\mathrm{Au}(111)$ surface $^{17}$ after the desorption of I adatoms. According to a SFG study on $\left[\mathrm{C}_{4} \mathrm{mim}\right]\left[\mathrm{PF}_{6}\right]$, a structural change in the imidazolium ring from an edge-on to a face-on orientation occurs with the decrease in potential. ${ }^{9}$

Figure 3 shows STM images of samples obtained by immersion of a $\mathrm{Au}(111)$ electrode in $\left[\mathrm{C}_{4} \mathrm{mim}\right][\mathrm{I}]$, followed by washing with acetone. On the terrace, several adlayers were obtained. One typical adlayer structure is shown in Fig. 3a, in which highly ordered bright spots are clearly observed. The distances between bright spots were measured to be $\sim 0.5 \mathrm{~nm}$, and this structure is assigned to I adatoms with a $(\sqrt{3} \times \sqrt{3})$ adlattice. ${ }^{22}$ Furthermore, at different locations, characteristic patterns, i.e., hexagons, often appeared in the adlayer, as shown in Fig. $3 \mathrm{~b}$. The hexagons are formed by compression of the adlattice of iodine. As reported in a previous study, two distinct series of incommensurate adlattices are formed, namely, a centered rectangular phase $c(p \times \sqrt{3})$ and a rotated hexagonal phase, depending upon the increase in coverage and the electrode potential. ${ }^{20}$ Indeed, the distances between bright spots were $\sim 0.45 \mathrm{~nm}$ and the atomic rows of iodine were distorted. However, the hexagonal pattern randomly appeared and the periodicity was different from that of the I adatoms prepared from a KI aqueous solution. ${ }^{22}$ This behavior is due to the higher concentration of iodide in $\left[\mathrm{C}_{4} \mathrm{mim}\right][\mathrm{I}]$. The small peak observed at $-1.15 \mathrm{~V}$ in the $\mathrm{CV}$ profile may be assigned to a phase transition of highly compressed I adatoms. Strikingly, characteristic nanostructures with square arrangements were observed on the I-Au(111) surface, as shown in Fig. 3c. The intermolecular distance between cavities was approximately $0.8 \mathrm{~nm}$, and careful inspection revealed I adatoms among the ring nanostructures. Judging from their shape and size, the nanostructured rings are likely to be composed of four $\left[\mathrm{C}_{4} \mathrm{mim}\right]$ cations. Adsorption of $\left[\mathrm{C}_{4} \mathrm{mim}\right]^{+}$is also supported by the N1s XPS 
(a)

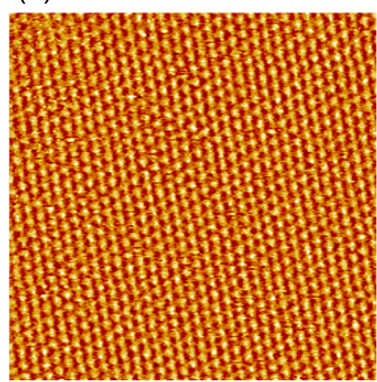

(c)

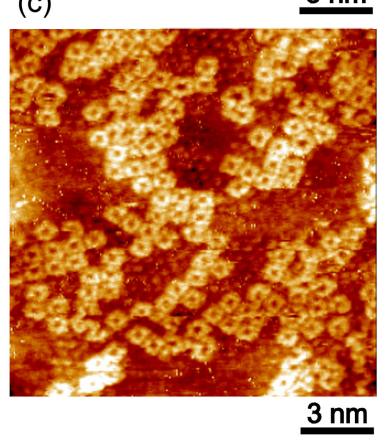

(b)

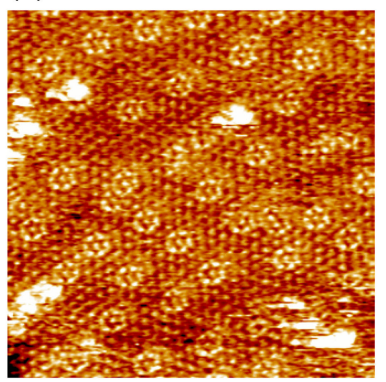

(d)

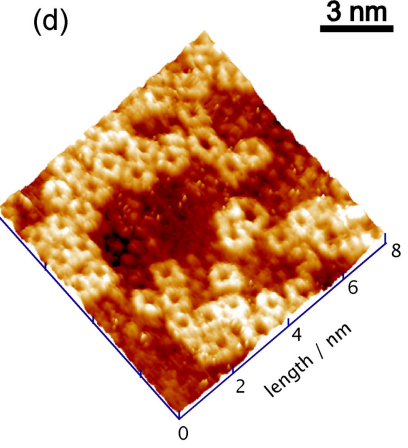

Figure 3. Typical STM images $\left(15 \times 15 \mathrm{~nm}^{2}\right)$ of (a) $(\sqrt{3} \times \sqrt{3})$ and (b) $c(p \times \sqrt{3})$ for I adatoms, and (c) a nanostructured $\left[\mathrm{C}_{4} \mathrm{mim}\right]^{+}$ adlayer on $\mathrm{Au}(111)$ observed under ambient conditions. (d) A height-shaded image showing a close-up view of (c). The bias voltage and tunneling current were (a) $0.30 \mathrm{~V}$ and $5 \mathrm{nA}$, (b) $0.10 \mathrm{~V}$ and $5 \mathrm{nA}$, and (c) $0.02 \mathrm{~V}$ and $5 \mathrm{nA}$.

spectrum shown in Fig. 2b. A height-shaded view of the electrode surface is shown in Fig. 3d. Several shapes of various sizes are clearly seen, suggesting that the nanostructured rings are formed by hydrophobic interactions among the butyl groups of the $\left[\mathrm{C}_{4} \mathrm{mim}\right]$ cations. Thus, the bright ring structures can be assigned as assemblies of several $\left[\mathrm{C}_{4} \mathrm{mim}\right]$ cations.

\section{Conclusions}

The electrochemical behavior and specific adsorption of $\left[\mathrm{C}_{4} \mathrm{mim}\right][\mathrm{I}]$ on a $\mathrm{Au}(111)$ electrode surface were investigated via voltammetric analyses, XPS, and STM. The electrochemical potential window of $\left[\mathrm{C}_{4} \mathrm{mim}\right][\mathrm{I}]$ was estimated to be approximately $2 \mathrm{~V}$. The reductive desorption of I adatoms was observed at $-2.17 \mathrm{~V}$ vs. $\mathrm{Fc} / \mathrm{Fc}^{+}$as a one-electron reduction process of I adatoms. The

electrochemical reductive desorption of I adatoms was supported by the XPS results. STM images revealed the formation of highly ordered I adatoms composed of $c(p \times \sqrt{3})$ structures and characteristic nanostructured rings consisting of $\left[\mathrm{C}_{4} \mathrm{mim}\right]$ cations. The findings in this study will contribute to not only the control of electron transfer and the understanding of $\mathrm{Au}$ dissolution processes at IL interfaces, but also the utilization of ILs for the assembly and construction of cation-based nanostructures.

\section{Acknowledgment}

This work was supported in part by a Grant-in-Aid for Science Research (B) (No. 27384701) from MEXT, Japan.

\section{References}

1. F. Endres, O. Höfft, N. Borisenko, L. H. Gasparotto, A. Prowald, R. Al-Salman, T. Carstens, R. Atkin, A. Bund, and S. Z. E. Abedin, Phys. Chem. Chem. Phys., 12, 1724 (2010).

2. M. V. Fedorov and A. A. Kornyshev, Chem. Rev., 114, 2978 (2014).

3. T. Cremer, M. Stark, A. Deyko, H.-P. Steinrück, and F. Maier, Langmuir, 27, 3662 (2011).

4. S. Yoshimoto, R. Taguchi, R. Tsuji, H. Ueda, and K. Nishiyama, Electrochem. Commun., 20, 26 (2012).

5. Y. Z. Su, J. W. Yan, M. G. Li, M. Zhang, and B. W. Mao, J. Phys. Chem. C, 117, 205 (2013).

6. O. M. Magnussen, Chem. Rev., 102, 679 (2002).

7. S. Ye, T. Kondo, N. Hoshi, J. Inukai, S. Yoshimoto, M. Osawa, and K. Itaya, Electrochemistry, 77, 2 (2009).

8. S. Yoshimoto and K. Itaya, Annu. Rev. Anal. Chem., 6, 213 (2013).

9. S. Baldelli, Acc. Chem. Res., 41, 421 (2008).

10. S. Caporali, U. Bardi, and A. Lavacchi, J. Electron Spec. Rel. Phenom., 151, 4 (2006).

11. C. Kolbeck, M. Killian, F. Maier, N. Paape, P. Wasserscheid, and H.-P. Steinrück, Langmuir, 24, 9500 (2008).

12. K. Tamura, S. Miyaguchi, K. Sakaue, Y. Nishihata, and J. Mizuki, Electrochem. Commun., 13, 411 (2011).

13. K. Tamura and Y. Nishihata, J. Phys. Chem. C, 120, 15691 (2016).

14. K. Motobayashi, K. Minami, N. Nishi, T. Sakka, and M. Osawa, J. Phys. Chem. Lett., 4, 3110 (2013).

15. Y.-Z. Su, Y.-C. Fu, J.-W. Yan, Z.-B. Chen, and B.-W. Mao, Angew. Chem., Int. Ed., 48, 5148 (2009).

16. R. Wen, B. Rahn, and O. M. Magnussen, Angew. Chem., Int. Ed., 54, 6062 (2015).

17. R. Wen, B. Rahn, and O. M. Magnussen, J. Phys. Chem. C, 120, 15765 (2016).

18. F. Buchner, K. Forster-Tonigold, B. Uhl, D. Alwast, N. Wagner, H. Farkhondeh, A. Groß, and R. J. Behm, ACS Nano, 7, 7773 (2013).

19. J. Clavilier, R. Faure, G. Guinet, and R. J. Durand, J. Electroanal. Chem., 107, 205 (1980).

20. T. Yamada, N. Batina, and K. Itaya, J. Phys. Chem., 99, 8817 (1995).

21. C. L. Bentley, A. M. Bond, A. F. Hollenkamp, P. J. Mahon, and J. Zhang, Anal. Chem., 85, 11319 (2013).

22. X. Gao, G. J. Edens, F.-C. Liu, A. Hamelin, and M. J. Weaver, J. Phys. Chem., 98, 8086 (1994). 